\title{
Mathematical Evaluation of Prediction Accuracy for Food Quality by Time Temperature Integrator of Intelligent Food Packaging through Virtual Experiments
}

\author{
Soo Dong Shim, ${ }^{1}$ Seung Won Jung, ${ }^{1,2}$ and Seung Ju Lee ${ }^{1,2}$ \\ ${ }^{1}$ Department of Food Science and Biotechnology, Dongguk University, 26 Pil-dong 3-ga, Jung-gu, Seoul 100-715, Republic of Korea \\ ${ }^{2}$ Center for Intelligent Agro-Food Packaging (CIFP), 81-1 Pil-dong 2-ga, Jung-gu, Seoul 100-272, Republic of Korea \\ Correspondence should be addressed to Seung Ju Lee; 1seungju@dongguk.edu
}

Received 14 May 2013; Accepted 2 July 2013

Academic Editor: Dong Sun Lee

Copyright (C) 2013 Soo Dong Shim et al. This is an open access article distributed under the Creative Commons Attribution License, which permits unrestricted use, distribution, and reproduction in any medium, provided the original work is properly cited.

Prediction of the quality of packaged foods using a colorimetric time temperature integrator (TTI) is affected by the types of kinetic models for the TTIs and the associated food qualities. Several types of kinetic models were applied for the TTI color change (four types) and food microbial growth (three types). To evaluate the prediction, a virtual experiment data of the food microbial growth were mathematically created by using the relevant kinetic models. In addition to the kinetic models, two types of temperaturedependent models (Arrhenius and square root models) were used in the calculation. Among the four types of TTIs, M2-3510 or S type for Pseudomonas spp. and M type for Listeria monocytogenes and Escherichia coli showed the least erroneous results. Overall, a suitable TTI could be selected for each food microorganism, based on the prediction accuracy.

\section{Introduction}

During the storage and distribution of packaged food, variations in temperature can deteriorate the quality of the food. Time temperature integrators (TTIs) are used to monitor food quality changes, based on time-temperature history. The key issue in TTI studies is the accuracy of predicting the food qualities, using the relevant kinetic and temperaturedependent models. TTIs have been applied to various foods, including meat, dairy products, fish, fruit, and vegetables [15]. Commercial TTIs include a number of enzymatic (biological), diffusion (physical), and polymer based (chemical) types, among which enzymatic TTIs are most commonly applied to foods [6].

The mechanism of food quality prediction by TTIs is described by the kinetic and temperature-dependent models for TTI color and food quality changes [3]. At first, the TTI color change under dynamic temperature conditions is kinetically analyzed to produce a $T_{\text {eff }}$ which is an apparent temperature representing the time-temperature history. In conventional analysis, the $n$th order kinetic equations and the Arrhenius equation for temperature dependence are used.
Secondly, it is assumed that this $T_{\text {eff }}$ is also the temperature experienced by the food. The corresponding quality values then are estimated by using the $T_{\text {eff }}$ with the relevant kinetic and temperature dependent model [7]. However, it is generally found that microbial growth in foods, one of the most important food quality factors, does not always follow the $n$th order reaction and that also temperature dependence does not always correspond to the Arrhenius equation [811]. This draws into question the validity of the existing prediction method. Ellouze and Augustin [12] applied just a few models for the food microorganism growth associated with TTI, due to the limitations of experimental approach. The mathematical approach would, however, be a robust solution to rigorously examine a number of cases.

Predictive mathematical models in food microbiology can be grouped into primary, secondary, and tertiary, according to the development stage. Primary models describe the change of the microbial level with time under particular environmental and cultural conditions. Several primary models have been developed, such as the Monod model, the Gompertz function, the Baranyi and Roberts model, and new logistic model [13-15] which can generate information 


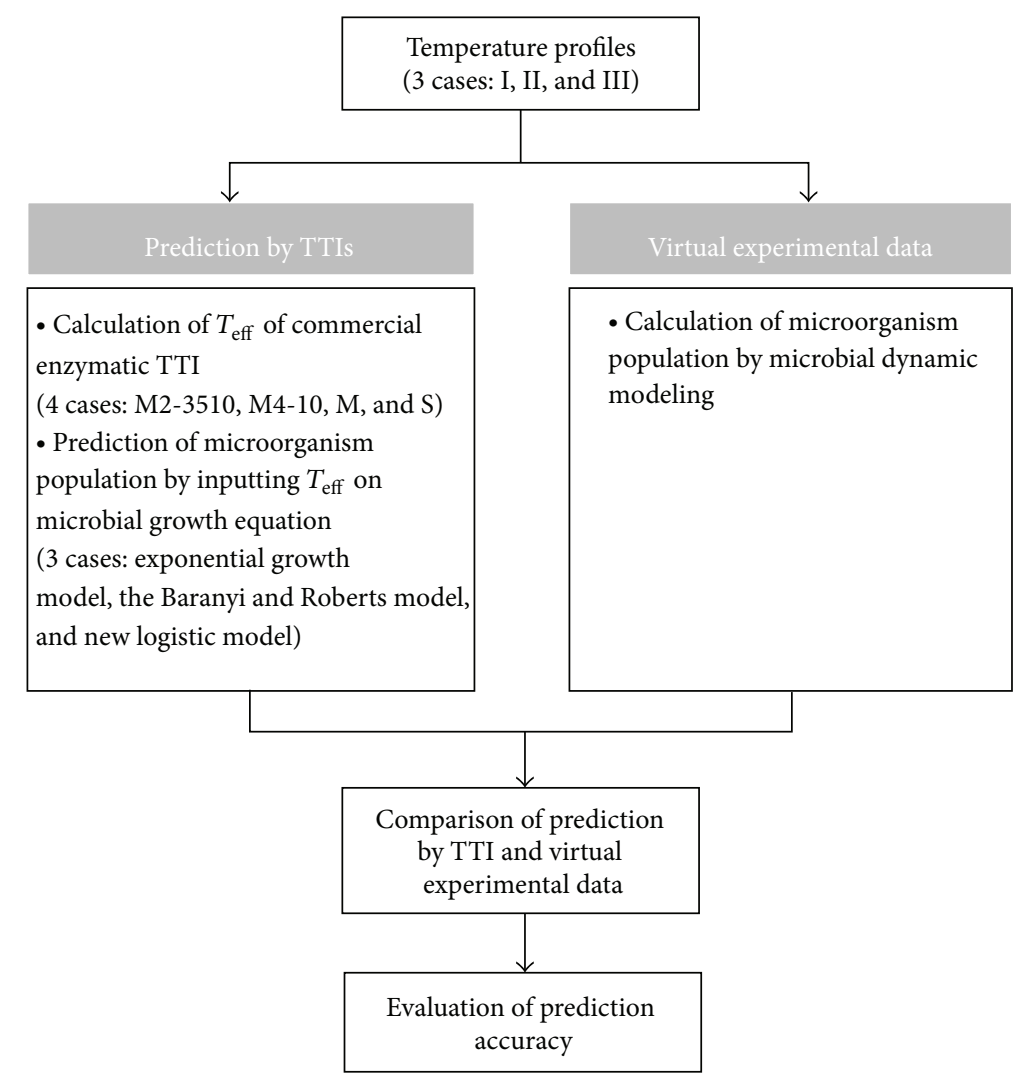

FIGURE 1: Flowchart for mathematical simulations of prediction by TTI and virtual data of food microorganism population.

about microorganisms, such as the generation time, lag phase duration, growth rate, and maximum population density. Secondary growth models illustrate the response of one or more parameters of a primary model, which alter due to changes in environmental and cultural conditions (temperature, $\mathrm{pH}$, water activity, etc.). Tertiary models are applications of one or more primary and secondary models, incorporated into a computer software package $[16,17]$. Several microbial modeling software packages have been developed to facilitate the prediction of microbial level with a variety of the growth models, the most popular being PMP, DMFit, and ComBase Predictor. The developed tertiary models now are all available via the Internet.

Packaged foods are stored either under isothermal or dynamic thermal conditions. Kinetic models were originally developed based on isothermal conditions, and so, solutions under dynamic conditions should be numerically executed. Therefore, the whole range of time-temperature histories is divided into infinitesimal intervals within which the temperature is assumed to be constant, allowing kinetic models to be used to estimate the instantaneous change of microbial levels. The microbial level's changes at each interval are totally integrated by using a numerical method. Xanthiakos et al. [18] applied numerical analysis to predict the Listeria monocytogenes growth in pasteurized milk under dynamic conditions. Fujikawa and Morozumi [19] also numerically solved the new logistic model and square root model for modeling surface growth of Escherichia coli on agar plates under dynamic condition.

As mentioned, there is an ambiguity in food quality predictions by TTIs with nonconventional models not following the $n$th order reaction and the Arrhenius equation. So, it would be ideal to perform as many experiments as possible in order to determine the prediction accuracy for combinations of TTIs and associated foods. However, in this study, virtual experiments were mathematically conducted as an alternative solution. Four commercial products of enzymatic TTIs with the relevant parameters known from some literatures [2, $4,20]$ were considered for modeling. Three typical models for the growth of actual pathogenic microorganisms were selected and used, not only for the prediction, but also as a virtual experiment of the microbial deterioration of packaged foods. The plausible storages of packaged foods under dynamic conditions were virtually simulated, in which the changes in the microorganism concentration were compared with predicted values by TTIs and virtual experimental data.

\section{Materials and Methods}

2.1. Prediction of Food Microbial Growth from TTIs' Color. The prediction of food qualities from TTIs' color changes under dynamic temperature conditions is executed according to a standard procedure (Figure 1) as follows: (i) a TTI color index is kinetically analyzed to produce a $T_{\text {eff }}$ which is 


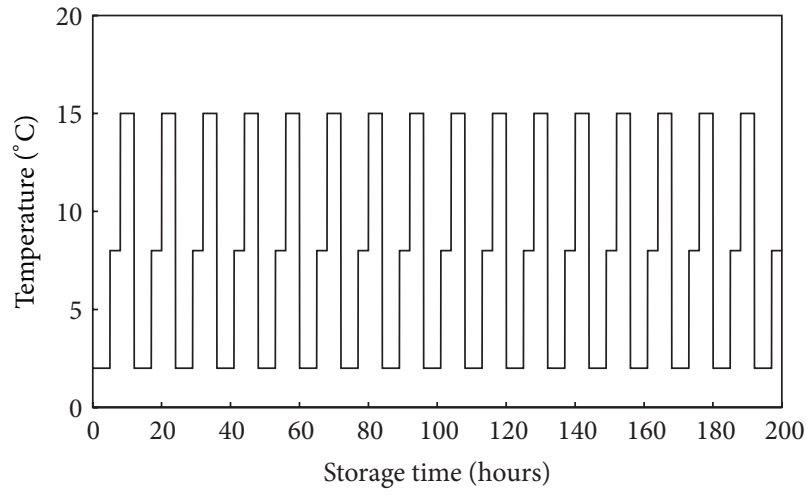

(a)

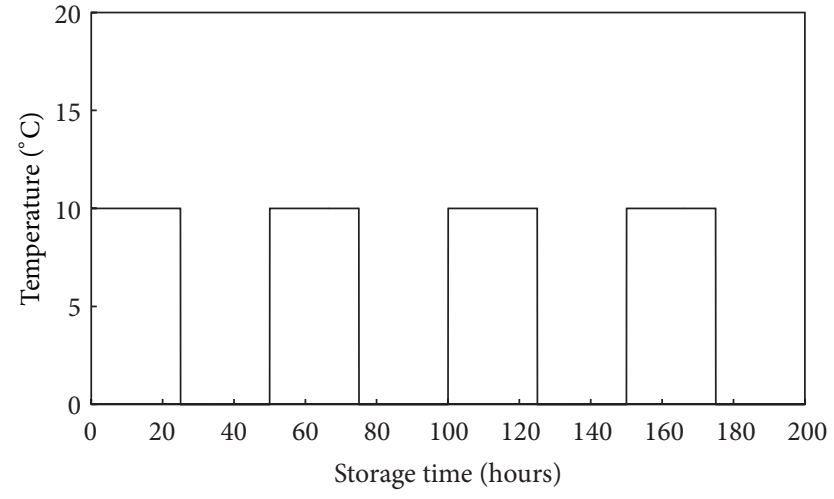

(b)

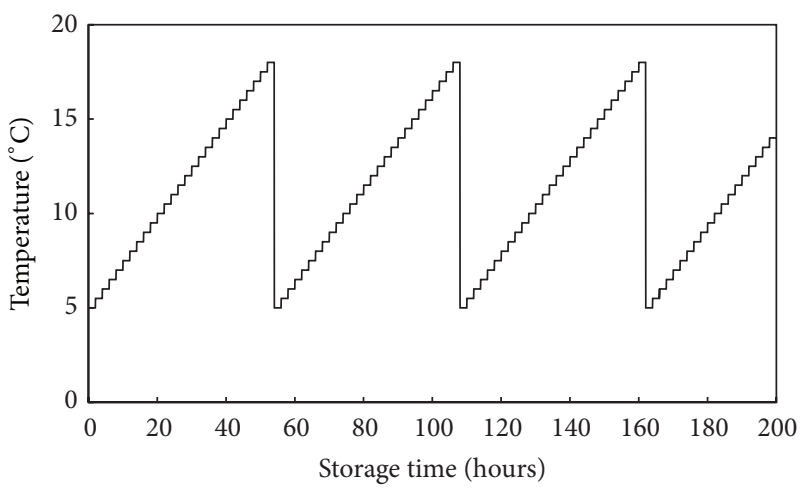

(c)

FIGURE 2: Time-temperature profiles for three cases. (a): Case I, (b): Case II, and (c): Case III.

an apparent temperature representing the time temperature history; (ii) it is assumed that this $T_{\text {eff }}$ is also the temperature experienced by the food; (iii) then, the corresponding quality values are estimated by using the $T_{\text {eff }}$ with the relevant kinetic and temperature-dependent models $[2,7,20]$.

Four commercial products of enzymatic TTIs were modeled with the relevant parameters which are known from some literatures (Table 1). The TTI response is represented by a color index $(F)$, as described in (1) [3]. The $F$ value changes in the zero-order reaction as per

$$
\frac{\mathrm{d} F}{\mathrm{~d} t}=k,
$$

where $t$ is the time after activating the TTI and $k$ is the rate constant $\left(h^{-1}\right) . k$ is expressed by temperature dependency in the Arrhenius equation as

$$
k=k_{\text {ref }} \exp \left[-\frac{E_{a}}{R}\left(\frac{1}{T}-\frac{1}{T_{\text {ref }}}\right)\right],
$$

where $T_{\text {ref }}$ is a reference temperature, $k_{\text {ref }}$ is the rate constant $\left(h^{-1}\right)$ at $T_{\text {ref }}, E_{a}$ is the Arrhenius activation energy $(\mathrm{kJ} / \mathrm{moL})$, $R$ is the universal gas constant $\left(8.314 \times 10^{-3} \mathrm{~kJ} / \mathrm{moL} \cdot \mathrm{K}\right)$, and $T$ is absolute temperature $(\mathrm{K})[4]$.

However, (1) and (2) can be used only for isothermal conditions. For dynamic temperature conditions, Euler's
TABLE 1: Kinetic parameters for commercial products of enzymatic TTIs (M2-3510; M4-10; M; S; Vitsab International, Malmö, Sweden).

\begin{tabular}{lccc}
\hline TTI type & \multicolumn{3}{c}{ Kinetic parameters } \\
& $E_{a}(\mathrm{~kJ} / \mathrm{mol})$ & $k_{\mathrm{ref}}\left(\mathrm{h}^{-1}\right)$ & $T_{\text {ref }}(\mathrm{K})$ \\
\hline M2-3510 & $100 \pm 11$ & $4.760 \times 10^{-4}$ & 253 \\
M4-10 & $58 \pm 8$ & $1.700 \times 10^{-2}$ & 273 \\
M & $69 \pm 9$ & $1.315 \times 10^{-2}$ & 273 \\
S & $102 \pm 6$ & $9.671 \times 10^{-3}$ & 273 \\
\hline
\end{tabular}

method as a numerical solution was applied, as per (3) and (4) $[21]$ :

$$
F_{i+1}=F_{i}+\left(\frac{\mathrm{d} F}{\mathrm{~d} t}\right)_{i} \Delta t
$$

where $F_{i}$ is the color index at an instantaneous time $(t=\Delta t$. $i$ ). The $F$ gradient is derived as a function of temperature by substituting (2) into (1) as follows:

$$
\left(\frac{\mathrm{d} F}{\mathrm{~d} t}\right)_{i}=k_{\mathrm{ref}} \exp \left[-\frac{E_{a}}{R}\left(\frac{1}{T}-\frac{1}{T_{\text {ref }}}\right)\right]
$$


TABLE 2: Microbial growth equations and parameters for dynamic modeling.

\begin{tabular}{|c|c|c|c|c|}
\hline Growth model & Equations & Kinetic parameters & Microorganism & References \\
\hline $\begin{array}{l}\text { (i) Exponential } \\
\text { growth model }\end{array}$ & $\begin{array}{l}\text { (a) } \frac{\mathrm{d} N}{d t}=\mu_{\max } N \\
\text { (b) } \mu_{\max }=\mu_{\text {ref }} \exp \left[\frac{-E_{a}}{R}\left(\frac{1}{T}-\frac{1}{T_{\text {ref }}}\right)\right]\end{array}$ & $\begin{array}{c}N_{0}(\mathrm{CFU} / \mathrm{g}): 10^{3.0} \\
\mu_{\text {ref }}\left(\mathrm{h}^{-1}\right): 0.044 \\
E_{a}(\mathrm{~kJ} / \mathrm{mol}): 81.6 \\
T_{\text {ref }}\left({ }^{\circ} \mathrm{C}\right): 0 \\
R\left(\mathrm{~kJ} / \mathrm{mol} .^{\circ} \mathrm{C}\right): 8.314 \times 10^{-3}\end{array}$ & $\begin{array}{l}\text { Pseudomonas } \\
\text { spp. } \\
\text { (boque fish) }\end{array}$ & [4] \\
\hline $\begin{array}{l}\text { (ii) The Baranyi } \\
\text { and Roberts } \\
\text { model }\end{array}$ & $\begin{array}{l}\text { (c) } \frac{\mathrm{d}}{\mathrm{d} t} x=\mu_{\max }\left(\frac{q}{q+1}\right)\left(1-\frac{x}{x_{\max }}\right) x \\
\text { (d) } \frac{\mathrm{d}}{\mathrm{d} t} q=\mu_{\max } q \\
\text { (e) } \sqrt{\mu_{\max }}=b\left(T-T_{\min }\right)\end{array}$ & $\begin{array}{c}x_{0}(\mathrm{CFU} / \mathrm{mL}): 10^{3.0} \\
b\left(\mathrm{~h}^{-1 / 2} /{ }^{\circ} \mathrm{C}\right): 0.024 \\
T_{\min }\left({ }^{\circ} \mathrm{C}\right):-2.32 \\
q: 1 /\left\{\exp \left(h_{0}\right)-1\right\} h_{0}: 1.34 \\
x_{\max }(\mathrm{CFU} / \mathrm{mL}): 10^{8.5}\end{array}$ & $\begin{array}{l}\text { Listeria } \\
\text { monocytogenes } \\
\text { (pasteurized } \\
\text { milk) }\end{array}$ & [18] \\
\hline $\begin{array}{l}\text { (iii) New logistic } \\
\text { model (NLM) }\end{array}$ & $\begin{array}{l}\text { (f) } \frac{\mathrm{d} N}{\mathrm{~d} t}=\mu_{\max } N\left\{1-\left(\frac{N}{N_{\max }}\right)^{m}\right\}\left\{1-\left(\frac{N_{\min }}{N}\right)^{n}\right\} \\
\text { (g) } \sqrt{\mu_{\max }}=b\left(T-T_{0}\right)\end{array}$ & $\begin{array}{c}N_{0}(\mathrm{CFU} / \mathrm{mL}): 10^{3.6} \\
b\left(\mathrm{~h}^{-1 / 2} /{ }^{\circ} \mathrm{C}\right): 0.0426 \\
T_{0}\left({ }^{\circ} \mathrm{C}\right): 0.0349 \\
N_{\max }(\mathrm{CFU} / \mathrm{mL}): 10^{10.1} \\
m: 0.58 \\
N_{\min }(\mathrm{CFU} / \mathrm{mL}):\left\{1-\left(10^{-6}\right)\right\} N_{0} \\
n: 3.0\end{array}$ & $\begin{array}{c}\text { Escherichia coli } \\
\text { (agar plate) }\end{array}$ & [19] \\
\hline
\end{tabular}

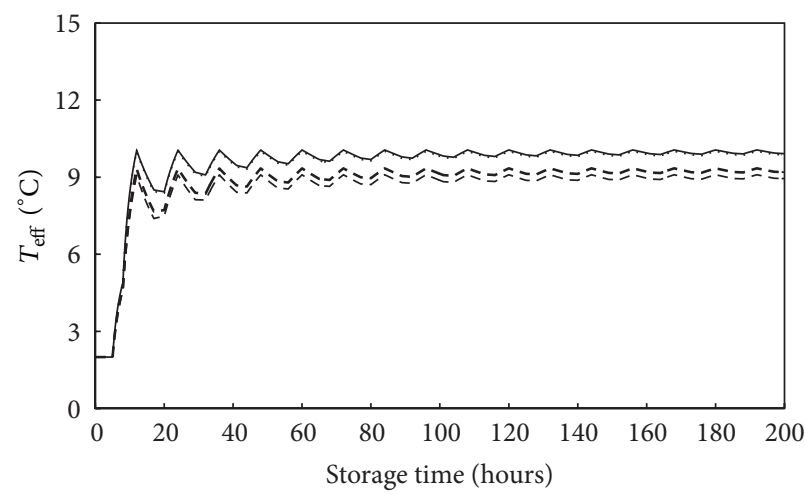

(a)

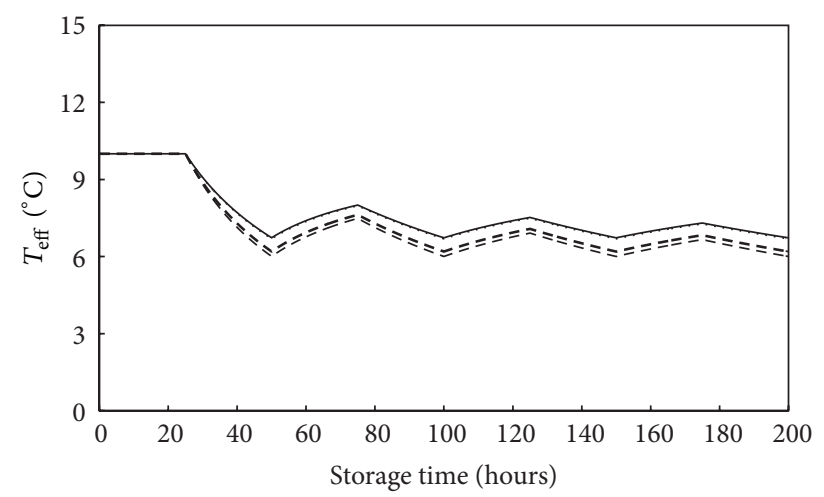

(b)

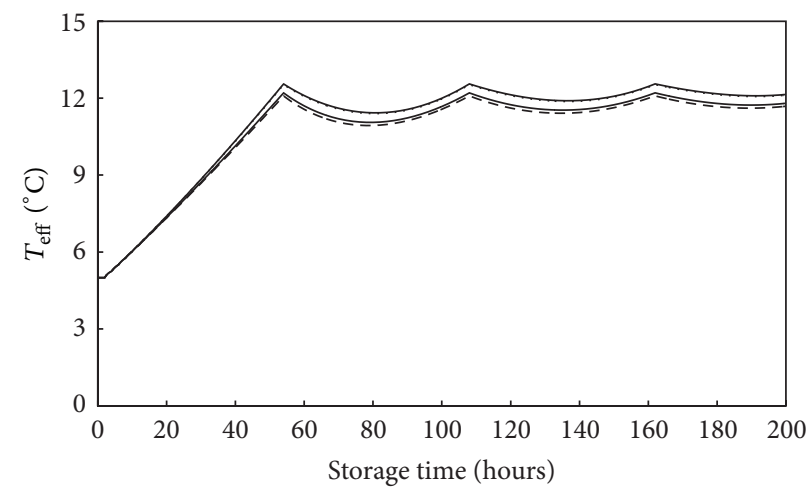

(c)

FIGURE 3: Storage time course of $T_{\text {eff }}$ of three cases. (a): Case I, (b): Case II, and (c): Case III. …. TTI M2-3510, - - - -: TTI M4-10, - - - -: TTI M, and —: TTI S.

To estimate $T_{\text {eff }}$, it is assumed that even though $F$ changes under dynamic condition, it is apparently under isothermal condition at $T_{\text {eff }}$, as described by (5):

$$
F_{0 \rightarrow t}=k_{\text {ref }} \exp \left[-\frac{E_{a}}{R}\left(\frac{1}{T_{\text {eff }}}-\frac{1}{T_{\text {ref }}}\right)\right] t,
$$

where $F_{0 \rightarrow t}$ is the $F$ value at time $t$ under dynamic conditions, which is numerically calculated by (3) and (4). $T_{\text {eff }}$ is calculated by (6) derived from

$$
T_{\mathrm{eff}}=\frac{E_{a} T_{\mathrm{ref}}}{E_{a}-R T_{\mathrm{ref}} \ln \left(F_{0 \rightarrow t} / k_{\mathrm{ref}} t\right)} .
$$




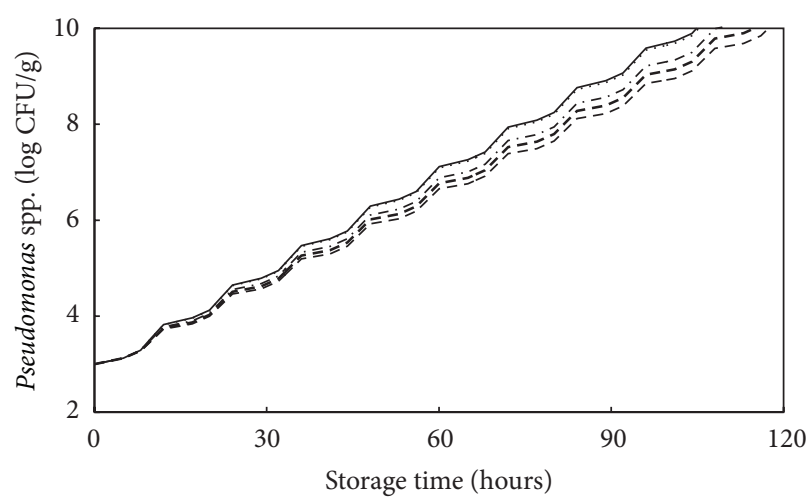

(a)

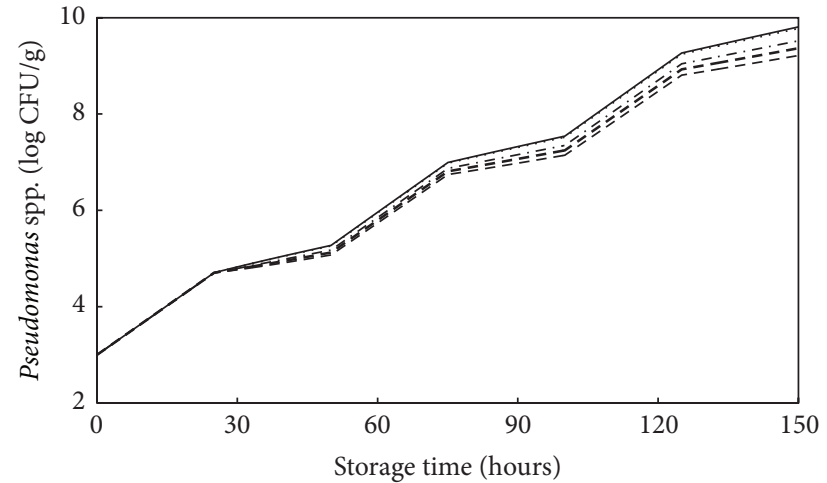

(b)

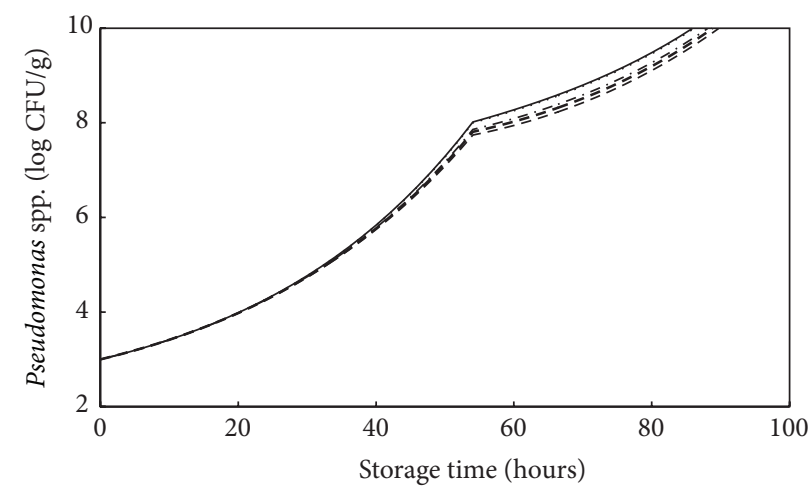

(c)

Figure 4: Pseudomonas spp. growth predicted by TTIs using exponential growth model. (a): Case I, (b): Case II, and (c): Case III. —·- : virtual experimental data, $\cdots \cdots$ : predicted by TTI M2-3510, - - - : TTI M4-10, - - - : TTI M, and _—: TTI S.

Finally, the food microbial growth is calculated by the relevant kinetic and temperature-dependent models (Table 2), which is assumed under isothermal condition at $T_{\text {eff. }}$. This part is dealt with in more details later.

The numerical solution was computed by visual basic application (VBA) of MS Excel 2007 [22].

2.2. Virtual Experiments for Food Microbial Growth. The plausible storages of packaged foods under dynamic conditions were virtually simulated. The time-temperature profiles were set up as the three types shown in Figures 2(a), 2(b), and 2(c). Case I $\left(2 \sim 15^{\circ} \mathrm{C}\right)$ and Case II $\left(0 \sim 10^{\circ} \mathrm{C}\right)$ refer to two profiles for dynamic storage testing of chilled fish [4]. Case III $\left(5 \sim 18^{\circ} \mathrm{C}\right)$ represents an exposure to the outdoors during cold chain. The total storage time was $200 \mathrm{~h}$ in total.

Three typical models for the growth of pathogenic microorganisms such as Pseudomonas spp., Listeria monocytogenes, and Escherichia coli were selected for a virtual experiment of the microbial deterioration of packaged foods.

Microbial growth was modeled using the primary and secondary models for the growth kinetics and temperature dependence, as shown in Table 2. The virtual data of the microbial growth were created through the numerical solution as previously mentioned, using differential forms of expression for dynamic temperature conditions.
2.3. Evaluation of Prediction Accuracy. Food microbial growth was compared between the predicted by TTI's color index and the virtual data, as shown in Figure 1. To evaluate the prediction error, statistical characteristic indices such as mean square error (MSE), bias factor, and accuracy factor were employed:

$$
\begin{gathered}
\text { MSE }=\frac{\text { RSS }}{n}=\frac{\sum\left(N_{\text {data }}-N_{\text {predicted }}\right)^{2}}{n}, \\
\text { Bias factor }=10^{\left(\sum \log \left[N_{\text {data }} / N_{\text {predicted }}\right] / n\right)}, \\
\text { Accuracy factor }=10^{\left(\sum \log \left[N_{\text {predicted }} / N_{\text {data }}\right] / n\right)},
\end{gathered}
$$

where $N$ is the microbial growth level and $n$ is the number of observations.

\section{Results and Discussion}

3.1. Prediction of Food Microbial Growth from TTIs' Color. As aforementioned, the time-temperature histories that TTIs and the packaged food virtually experienced were represented by three types of profiles (Figure 2) for dynamic storage tests of chilled fish and an exposure to the outdoors during cold chain. Also it was assumed that the fictitious TTIs 


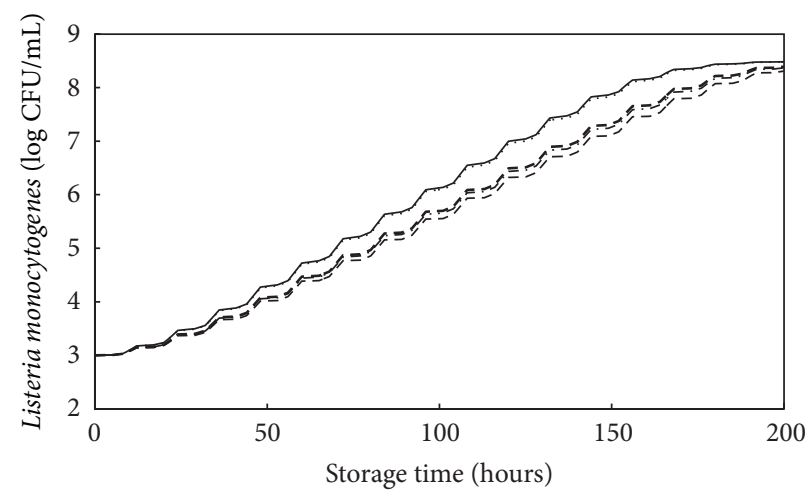

(a)

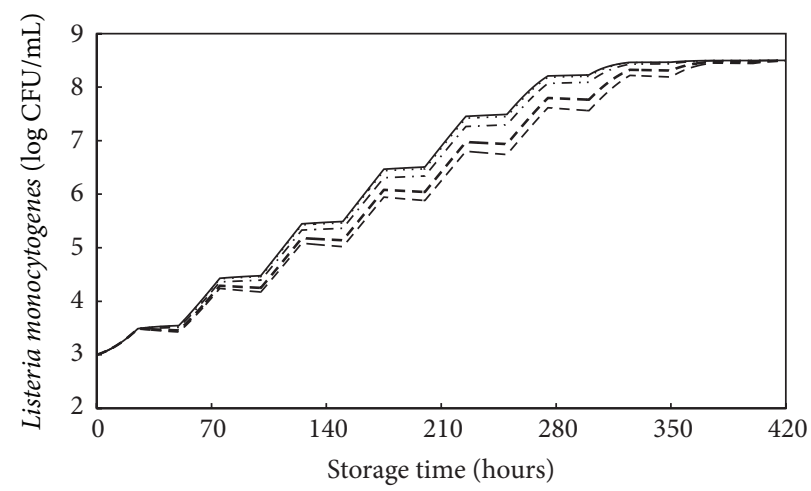

(b)

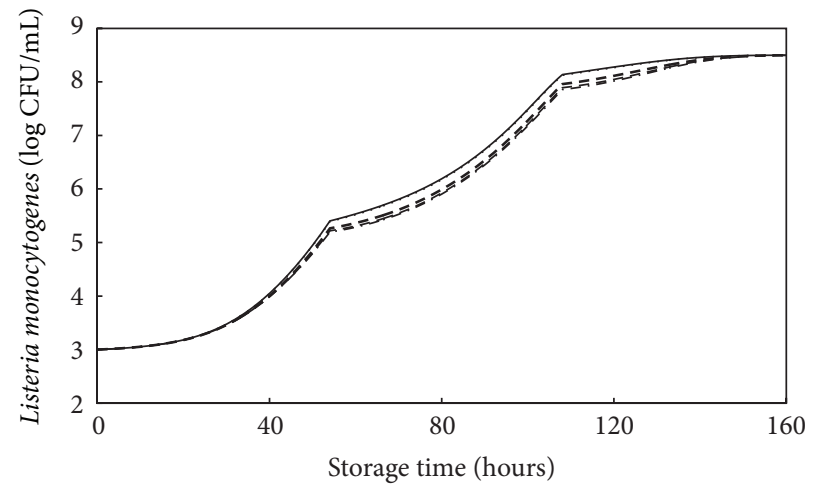

(c)

FIgure 5: Listeria monocytogenes growth predicted by TTIs using Baranyi and Roberts model. (a): Case I, (b): Case II, and (c): Case III. - - virtual experimental data, …..: predicted by TTI M2-3510, - - - -: TTI M4-10, - - - -: TTI M, and ——: TTI S.

and foods experienced the same time-temperature history, so that their dimensions and thermal properties were not considered.

The $T_{\text {eff }}$ values of the enzymatic TTIs were computed by (6) as shown in Figure 3. The curves of M2-3510, M4-10, M, and $S$ showed a similar pattern in changes. The fluctuation of the curves reflected the dynamic storage conditions. The $T_{\text {eff }}$ levels for $S$ were the highest, followed by M2-3510, M, and M4-10. It was interesting that this order agreed with that of the $E_{a}$ of the TTIs. In Table 1 , the $E_{a}$ levels for $S$ are the largest, followed by M2-3510, M, and M4-10. In particular, the curves of S and M2-3510 are almost overlapped because they have similar $E_{a}$.

In case II, the overall levels of $T_{\text {eff }}$ decreased with time, whereas they reached an asymptote in the other cases. It is because the $T_{\text {eff }}$, the apparent temperature representing the time-temperature history, is affected by the interval between high and low in the temperature profiles (Figure 2). The big interval gap in Case II decelerates reaching an asymptote. However, Case III also has big interval but resides just shortly at the bottom level, so that the $T_{\text {eff }}$ levels stayed high and constant.

The predicted microbial growth from $T_{\text {eff }}$ is shown in Figures 4,5 , and 6 . The final microbial levels were estimated to be $9.0 \log \mathrm{CFU} / \mathrm{g}, 8.5 \log \mathrm{CFU} / \mathrm{mL}$, and $10.1 \log \mathrm{CFU} / \mathrm{mL}$ for Pseudomonas spp., L. monocytogenes, and E. coli, respectively.
3.2. Virtual Food Microbial Growth from Different Growth Models. The growth of the microorganisms could be illustrated by the mathematical models, characterized by the presence of lag, exponential, or stationary phase. The growth data of Pseudomonas spp. was virtually created by the exponential growth model ((a) of Table 2)) [17] and was compared with that which was predicted from TTI's color index (Figure 4). The data and predicted curves showed the exponential phase only. It is known that the exponential growth model cannot include the lag and stationary phases of a typical microbial growth curve [17]. So a high limit of cell concentration was given at $9.0 \log \mathrm{CFU} / \mathrm{g}$ for further analysis. There were unusual fluctuations in the growth curves, quite unlike a typical smooth curve of bacterial exponential growth under isothermal conditions, which was likely due to the dynamic temperature conditions.

The growth data of L. monocytogenes was virtually created by the Baranyi and Roberts model ((c) and (d) of Table 2) [18]. The curves similarly had an asymptote at $8.5 \log \mathrm{CFU} / \mathrm{mL}$, representing a stationary phase (Figure 5). In comparison with the exponential growth model, the Baranyi and Roberts model includes the lag parameter $(q / q+1)$ and inhibition function $\left(1-x / x_{\max }\right)$ for the stationary phase.

The growth of $E$. coli was expressed by the new logistic model (NLM) ((f) of Table 2) [19], as shown in Figure 6. The data and predicted curves clearly exhibited lag and stationary 


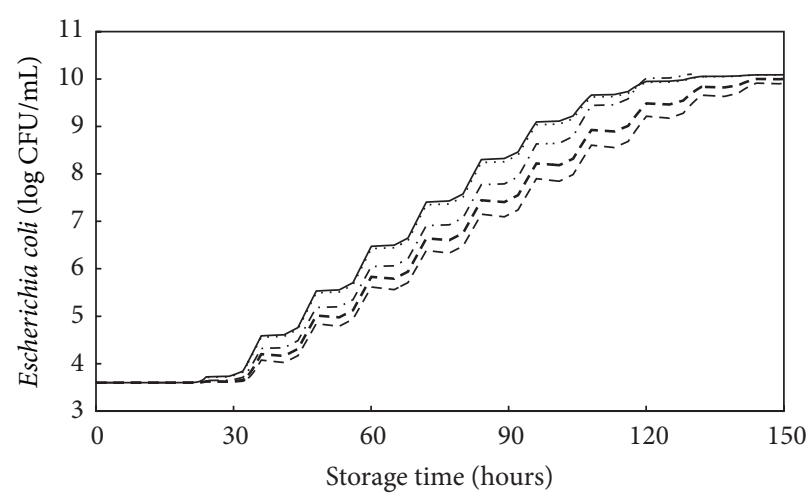

(a)

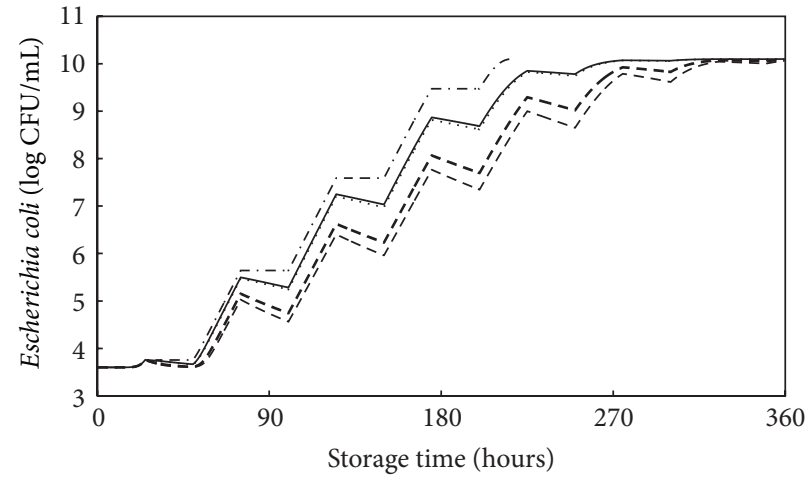

(b)

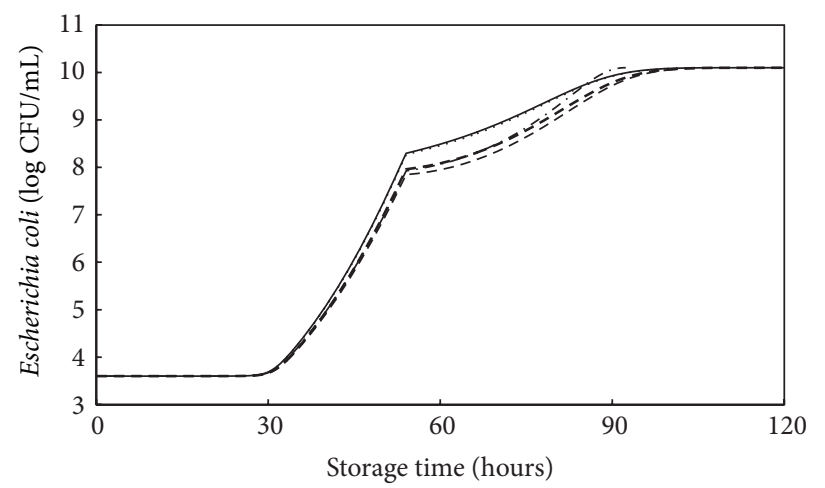

(c)

Figure 6: Escherichia coli growth predicted by TTIs using the new logistic model (NLM). (a): Case I, (b): Case II, and (c): Case III. —·-: virtual experimental data, $\cdots \cdots$ : predicted by TTI M2-3510, - - - -: TTI M4-10, - - - -: TTI M, and _—: TTI S.

phases at 3.6 $\log \mathrm{CFU} / \mathrm{mL}$ and $10.1 \log \mathrm{CFU} / \mathrm{mL}$, respectively. The lag and stationary phases were more pronounced than those of Figure 5, as the NLM has an additional variable (1 $\left.\left(N_{\min } / N\right)^{n}\right)$ relating the initial and final levels.

3.3. Evaluation of Prediction Accuracy. As shown in Figures 4, 5 , and 6 , there was the error between the predicted and virtual data. It was quantified by using several statistical parameters (Table 3).

The mean square error (MSE) values were estimated in the range of $0.000 \sim 0.023,0.000 \sim 0.030$, and $0.001 \sim 0.045$ for the exponential growth model, the Baranyi and Roberts model, and new logistic model (NLM), respectively, for all types of TTIs. The lower the MSE of the model is, the better the adequacy of the model to describe the data is [23]. This indicates that the exponential growth model was the most accurate one in the prediction. In particular, the Baranyi and Roberts model and new logistic model (NLM) had poor prediction from the M4-10 TTI under the Case II conditions.

The bias factors, as another measure of variability, were in the range of $0.971 \sim 1.030,0.946 \sim 1.042$, and $0.962 \sim 1.162$ for the exponential growth model, the Baranyi and Roberts model, and new logistic model (NLM), respectively, for all types of TTIs. Bias factor is a test parameter to evaluate the hypothesis that the model predicts the true value [24]. These results agreed with those of the MSE.
The accuracy factor values were $0.970 \sim 1.030,0.960 \sim$ 1.057, and 0.861 1.039 for the exponential growth model, the Baranyi and Roberts model, and new logistic model (NLM), respectively, for all types of TTIs. Accuracy factor is also used for the same purpose as the bias factor [23]. These results coincided with those of the MSE and bias factor.

Overall, on behalf of the statistical parameters, MSE was used to match the TTIs with suitable food microbial growth models (or corresponding microorganisms), resulting in M23510 or S type: exponential growth model and M type: Baranyi and Roberts model and new logistic model (NLM).

\section{Conclusions}

TTIs for intelligent food packaging are a useful tool to monitor the associated food qualities. However, the accuracy of predicting food qualities from the TTIs' color changes is variable, depending on a large number of factors. The conventional principles in the prediction are based on the $n$th order reaction kinetics and on the Arrhenius temperaturedependent model for microbial growth. Unfortunately, most food pathogenic microbial growth does not follow the $n$th order reaction, but it is more similar to empirical growth models. In this study, nonconventional growth models were applied to the prediction of food microbial quality using TTIs. Virtual experiments were mathematically conducted, 
TABLE 3: Evaluation of prediction accuracy for growth of Pseudomonas spp., Listeria monocytogenes, and Escherichia coli by TTIs in terms of various statistical parameters.

\begin{tabular}{|c|c|c|c|c|c|c|c|c|c|c|}
\hline \multirow{2}{*}{\multicolumn{2}{|c|}{ TTI type $\begin{array}{c}\text { Case for } \\
\text { temperature profile }\end{array}$}} & \multicolumn{3}{|c|}{$\begin{array}{l}\text { Exponential growth model } \\
\text { (Pseudomonas spp.) }\end{array}$} & \multicolumn{3}{|c|}{$\begin{array}{l}\text { The Baranyi and Roberts model } \\
\text { (Listeria monocytogenes) }\end{array}$} & \multicolumn{3}{|c|}{$\begin{array}{c}\text { New logistic model (NLM) } \\
\text { (Escherichia coli) }\end{array}$} \\
\hline & & MSE & Bias factor & Accuracy factor & MSE & Bias factor & Accuracy factor & MSE & Bias factor & Accuracy factor \\
\hline \multirow{3}{*}{ M2-3510 } & I & 0.000 & 0.974 & 1.027 & 0.018 & 0.949 & 1.053 & 0.033 & 0.967 & 1.034 \\
\hline & II & 0.000 & 0.985 & 1.016 & 0.003 & 0.988 & 1.012 & 0.006 & 1.053 & 0.950 \\
\hline & III & 0.001 & 0.989 & 1.011 & 0.010 & 0.978 & 1.023 & 0.020 & 0.982 & 1.018 \\
\hline \multirow{3}{*}{ M4-10 } & I & 0.000 & 1.030 & 0.970 & 0.001 & 1.014 & 0.987 & 0.007 & 1.066 & 0.938 \\
\hline & II & 0.000 & 1.019 & 0.982 & 0.030 & 1.042 & 0.960 & 0.045 & 1.162 & 0.861 \\
\hline & III & 0.023 & 1.010 & 0.991 & 0.000 & 0.998 & 1.002 & 0.002 & 1.012 & 0.988 \\
\hline \multirow{3}{*}{ M } & I & 0.000 & 1.015 & 0.985 & 0.000 & 0.994 & 1.006 & 0.001 & 1.036 & 0.965 \\
\hline & II & 0.000 & 1.009 & 0.991 & 0.013 & 1.025 & 0.975 & 0.029 & 1.130 & 0.885 \\
\hline & III & 0.014 & 1.004 & 0.996 & 0.001 & 0.992 & 1.008 & 0.005 & 1.004 & 0.996 \\
\hline \multirow{3}{*}{ S } & I & 0.000 & 0.971 & 1.030 & 0.022 & 0.946 & 1.057 & 0.039 & 0.962 & 1.039 \\
\hline & II & 0.000 & 0.983 & 1.018 & 0.005 & 0.986 & 1.014 & 0.005 & 1.047 & 0.955 \\
\hline & III & 0.001 & 0.988 & 1.013 & 0.012 & 0.976 & 1.024 & 0.022 & 0.980 & 1.020 \\
\hline
\end{tabular}

in which TTIs and food microbial qualities were all mathematically modeled using known parameters. Overall, suitable TTIs could be selected for each microorganism in food to be predicted accurately.

\section{Acknowledgments}

This research was supported by the R\&D Convergence Center Support Program (710003-03) of the Ministry for Food, Agriculture, Forestry and Fisheries, Republic of Korea. The authors wish to thank $3 \mathrm{M}$ Korea for the supply of material and financial support.

\section{References}

[1] B. Fu, P. S. Taoukis, and T. P. Labuza, "Predictive microbiology for monitoring spoilage of dairy products with timetemperature integrators," Journal of Food Science, vol. 56, no. 5, pp. 1209-1215, 1991.

[2] M. C. Giannakourou, K. Koutsoumanis, G. J. E. Nychas, and P. S. Taoukis, "Field evaluation of the application of time temperature integrators for monitoring fish quality in the chill chain," International Journal of Food Microbiology, vol. 102, no. 3, pp. 323-336, 2005.

[3] M. C. Giannakourou and P. S. Taoukis, "Systematic application of time temperature Integrators as tools for control of frozen vegetable quality," Journal of Food Science, vol. 67, no. 6, pp. 2221-2228, 2002.

[4] P. S. Taoukis, K. Koutsoumanis, and G. J. E. Nychas, "Use of time-temperature integrators and predictive modelling for shelf life control of chilled fish under dynamic storage conditions," International Journal of Food Microbiology, vol. 53, no. 1, pp. 2131, 1999.

[5] H. Vaikousi, C. G. Biliaderis, and K. P. Koutsoumanis, "Applicability of a microbial Time Temperature Indicator (TTI) for monitoring spoilage of modified atmosphere packed minced meat," International Journal of Food Microbiology, vol. 133, no. 3, pp. 272-278, 2009.
[6] A. López-Gómez, P. S. Fernández, A. Palop et al., "Food safety engineering: an emergent perspective," Food Engineering Reviews, vol. 1, no. 1, pp. 84-104, 2009.

[7] F. Hindra and O. D. Baik, "Kinetics of quality changes during food frying," Critical Reviews in Food Science and Nutrition, vol. 46, no. 3, pp. 239-258, 2006.

[8] F. Diez-Gonzalez, D. Belina, T. P. Labuza, and A. Pal, "Modeling the growth of Listeria monocytogenes based on a time to detect model in culture media and frankfurters," International Journal of Food Microbiology, vol. 113, no. 3, pp. 277-283, 2007.

[9] K. Grijspeerdt and K. De Reu, "Practical application of dynamic temperature profiles to estimate the parameters of the square root model," International Journal of Food Microbiology, vol. 101, no. 1, pp. 83-92, 2005.

[10] L. Huang, "Description of growth of Clostridium perfrigens in cooked beef with multiple linear models," Food Microbiology, vol. 19, no. 6, pp. 577-587, 2002.

[11] M. Raccach and M. Mellatdoust, "The effect of temperature on microbial growth in orange juice," Journal of Food Processing and Preservation, vol. 31, no. 2, pp. 129-142, 2007.

[12] M. Ellouze and J. C. Augustin, "Applicability of biological time temperature integrators as quality and safety indicators for meat products," International Journal of Food Microbiology, vol. 138, no. 1-2, pp. 119-129, 2010.

[13] N. C. Choi, J. W. Choi, S. B. Kim, and D. J. Kim, "Modeling of growth kinetics for Pseudomonas putida during toluene degradation," Applied Microbiology and Biotechnology, vol. 81, no. 1, pp. 135-141, 2008.

[14] V. K. Juneja, M. V. Melendres, L. Huang, J. Subbiah, and H. Thippareddi, "Mathematical modeling of growth of Salmonella in raw ground beef under isothermal conditions from 10 to $45^{\circ}$ C, International Journal of Food Microbiology, vol. 131, no. 2-3, pp. 106-111, 2009.

[15] H. Fujikawa and S. Morozumi, "Modeling Staphylococcus aureus growth and enterotoxin production in milk," Food Microbiology, vol. 23, no. 3, pp. 260-267, 2006.

[16] A. H. Geeraerd, V. P. Valdramidis, and J. F. Van Impe, "GInaFiT, a freeware tool to assess non-log-linear microbial survivor 
curves," International Journal of Food Microbiology, vol. 102, no. 1, pp. 95-105, 2005.

[17] N. Gómez, D. García, I. Álvarez, J. Raso, and S. Condón, "A model describing the kinetics of inactivation of Lactobacillus plantarum in a buffer system of different $\mathrm{pH}$ and in orange and apple juice," Journal of Food Engineering, vol. 70, no. 1, pp. 7-14, 2005.

[18] K. Xanthiakos, D. Simos, A. S. Angelidis, G. J. E. Nychas, and K. Koutsoumanis, "Dynamic modeling of Listeria monocytogenes growth in pasteurized milk," Journal of Applied Microbiology, vol. 100, no. 6, pp. 1289-1298, 2006.

[19] H. Fujikawa and S. Morozumi, "Modeling surface growth of Escherichia coli on agar plates," Applied and Environmental Microbiology, vol. 71, no. 12, pp. 7920-7926, 2005.

[20] T. F. Mendoza, B. A. Welt, S. Otwell, A. A. Teixeira, H. Kristonsson, and M. O. Balaban, "Kinetic parameter estimation of timetemperature integrators intended for use with packaged fresh seafood," Journal of Food Science, vol. 69, no. 3, pp. FMS90FMS96, 2004.

[21] C. B. MacDonald, S. Gottlieb, and S. J. Ruuth, "A numerical study of diagonally split Runge-Kutta methods for PDEs with discontinuities," Journal of Scientific Computing, vol. 36, no. 1, pp. 89-112, 2008.

[22] H. J. Park, S. D. Shim, S. G. Min, and S. J. Lee, "Mathematical simulation of the temperature dependence of time temperature integrator (TTI) and meat qualities," Korean Journal for Food Science of Animal Resources, vol. 29, no. 3, pp. 349-355, 2009.

[23] T. Ross, "Indices for performance evaluation of predictive models in food microbiology," Journal of Applied Bacteriology, vol. 81, no. 5, pp. 501-508, 1996.

[24] P. Dalgaard and L. V. Jørgensen, "Predicted and observed growth of Listeria monocytogenes in seafood challenge tests and in naturally contaminated cold-smoked salmon," International Journal of Food Microbiology, vol. 40, no. 1-2, pp. 105-115, 1998. 


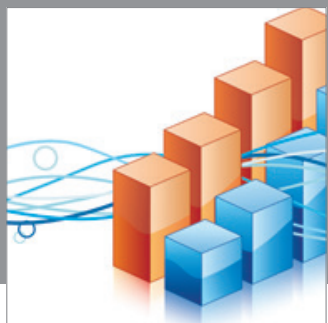

Advances in

Operations Research

mansans

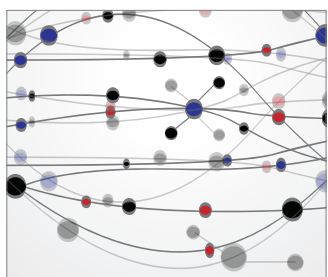

The Scientific World Journal
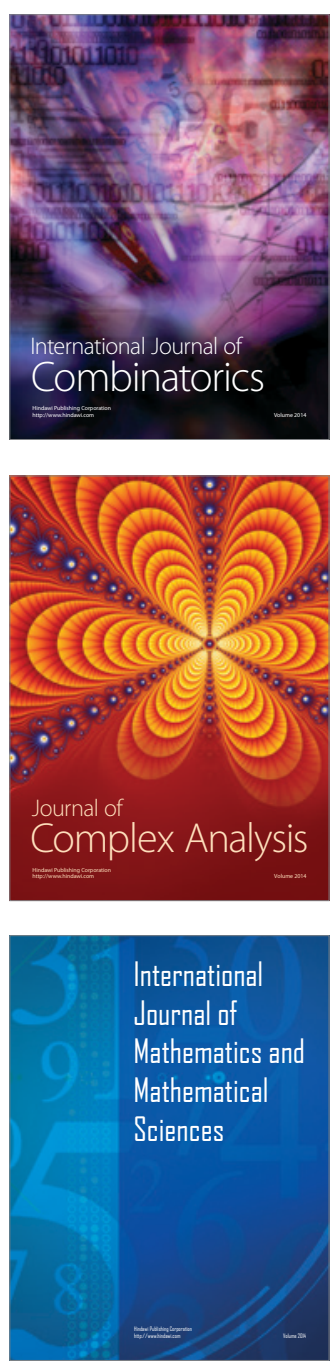
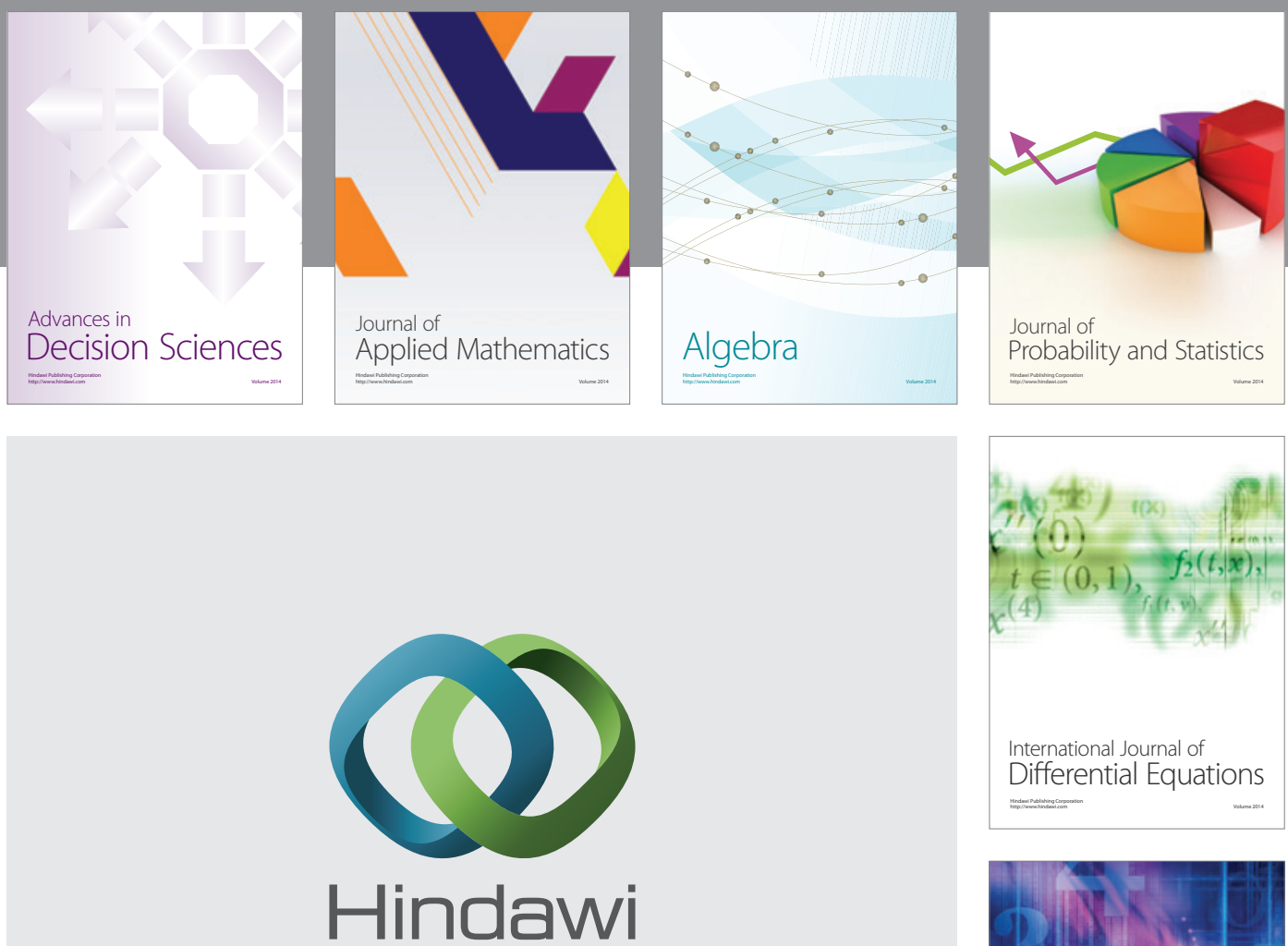

Submit your manuscripts at http://www.hindawi.com
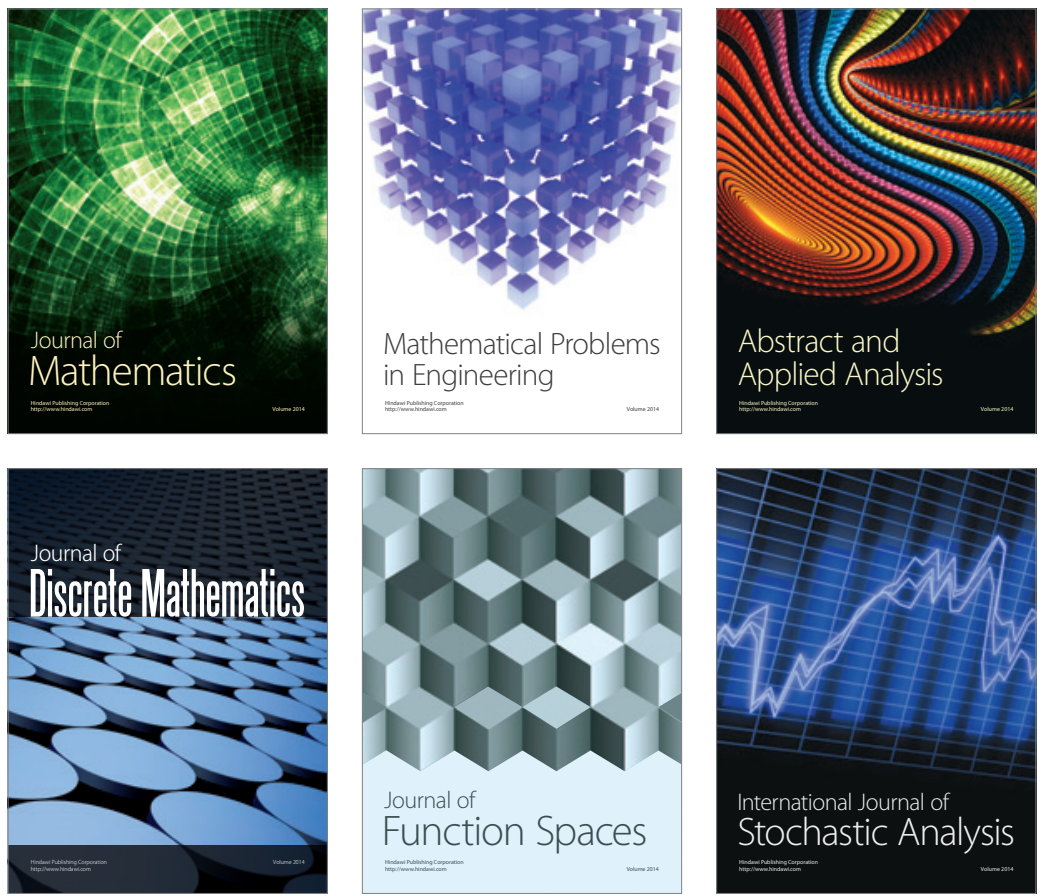

Journal of

Function Spaces

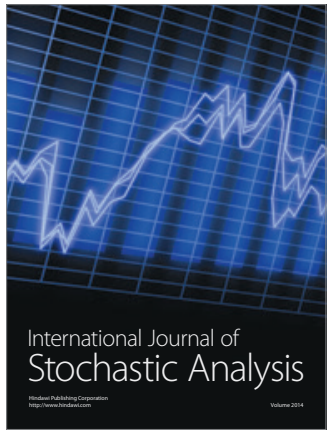

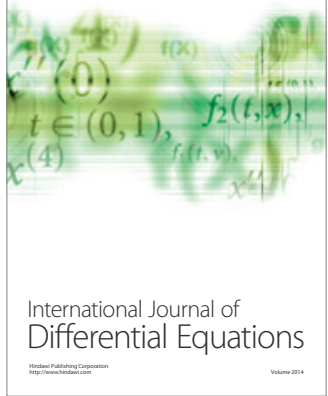
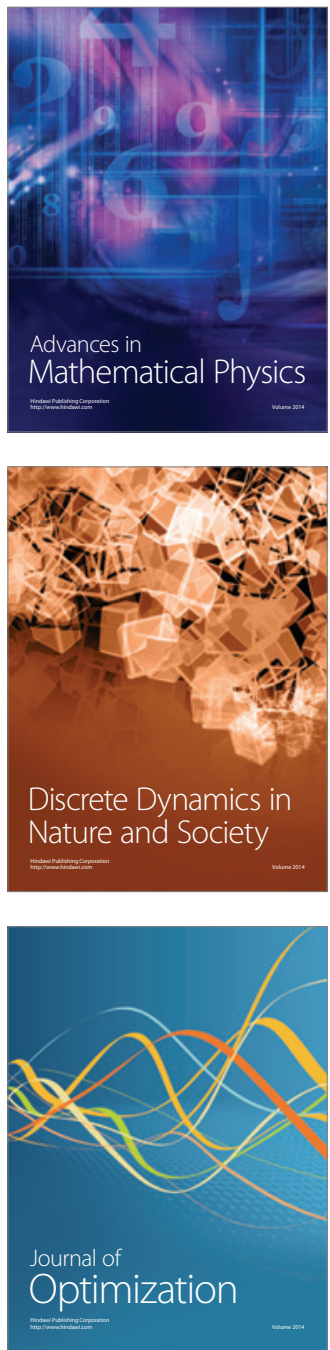